\title{
A escassez hídrica na Região Metropolitana de Campinas entre 2013-2015: a perspectiva de um desastre socialmente construído
}

\author{
Water scarcity in the Metropolitan Area of Campinas between \\ 2013 and 2015: the perspective of a socially constructed disaster
}

Tathiane Mayumi Anazawa ${ }^{[l]}$

\begin{abstract}
Resumo
No Brasil, especificamente na região Sudeste, os baixos índices pluviométricos iniciados em 2013 e intensificados durante 2014 e 2015 caracterizaram uma estiagem de caráter prolongado, resultando em uma escassez hídrica, um desastre socialmente construído. Uma das áreas mais afetadas por essa escassez hídrica foi a Região Metropolitana de Campinas (RMC). 0 objetivo deste trabalho foi apresentar elementos para a discussão da escassez hídrica ocorrida na RMC sob a perspectiva dos desastres socialmente construídos. A partir de uma análise de entrevistas semiestruturadas realizadas com atores envolvidos com a gestão dos recursos hídricos, foi possível observar que as medidas emergenciais que desconsideram a construção social do problema tiveram pouco efeito na resolução de conflitos.
\end{abstract}

Palavras-chave: água; desastre - aspectos sociais; escassez; percepção; regiões metropolitanas.

\begin{abstract}
In Brazil, specifically in the Southeast region, the low rainfall indexes that started in 2013 and were intensified during 2014 and 2015 characterized a prolonged drought, resulting in a water scarcity crisis, a socially constructed disaster. One of the most affected areas was the Metropolitan Area of Campinas. The aim of this work was to present elements in order to discuss the water scarcity that occurred in the Metropolitan Area of Campinas from the perspective of socially constructed disasters. Based on an analysis of semi-structured interviews carried out with actors involved in the management of water resources, it was possible to observe that emergency actions that disregard the social construction of the problem had little effect on conflict resolution.
\end{abstract}

Keywords: water; disaster - social aspects; scarcity; perception; metropolitan areas. 


\section{Introdução}

No Brasil, especificamente na região Sudeste, os baixos índices pluviométricos iniciados em 2013 e intensificados durante o verão de 2014 e de 2015 (Marengo e Alves, 2015) caracterizaram uma estiagem de caráter prolongado, resultando em uma escassez hídrica, denominada, também pela mídia e pelas diferentes instâncias de gestão dos recursos hídricos, "crise hídrica". Os agravantes dessa estiagem prolongada ainda puderam ser sentidos nos anos posteriores, com os baixos volumes armazenados de água nos reservatórios e que ainda não foram repostos, com perdas econômicas, além de evidenciar as desigualdades presentes no acesso à água, tanto em quantidade como em qualidade.

Pensando na situação vivenciada pelo estado de São Paulo, no período entre 2013 e 2015, especificamente a Região Metropolitana de Campinas, este trabalho considera essa situação como uma escassez hídrica e faz sua leitura como um desastre. Considerando a escassez hídrica diante dos elementos que compõem a dinâmica demográfica, ela pode atingir, em diferentes graus de severidade, as populações com características socioeconômicas e demográficas diferenciadas, localizadas em diversos territórios. 0 resultado desse processo, construído socialmente ao longo do tempo, é considerado um desastre. Nessa perspectiva, os desastres não são naturais.

Segundo Romero e Maskrey (1993), há que se diferenciar o fenômeno natural do desastre. 0 fenômeno natural consiste em toda manifestação da natureza, podendo ser previsível ou não, podendo provocar um desastre ou não. Já o desastre, que pode ter um fenômeno natural como evento deflagrador, somente se caracteriza como desastre quando ocasiona mudanças na vida da população. Desse modo, explicar os desastres pela abordagem da naturalização de um evento torna-se insuficiente. 0 desastre precisa ser entendido de forma mais abrangente, como um produto de uma combinação das ameaças (o físico) e a vulnerabilidade da sociedade (o social). 0 que implica a aceitação de que são as condições sociais historicamente constituídas de uma população as que determinam, em grande parte, o nível de destruição ou interrupção da rotina ou da vida das pessoas. Isso significa dizer que as ameaças físicas consistem em um fator necessário na fórmula dos desastres, porém, não se configuram como condição suficiente nem predominante em sua existência (Lavell Thomas e Franco, 1996; Valencio, 2013 e 2014).

Para o presente trabalho foi discutida a questão da escassez hídrica enquanto um desastre socialmente construído e ocorrido em áreas urbanas, envolvendo regiões metropolitanas que não apresentaram eventos de escassez hídrica com tamanha intensidade nos últimos anos. ${ }^{1}$ Nesse contexto, o objetivo deste trabalho consistiu em apresentar elementos para a discussão da escassez hídrica ocorrida na Região Metropolitana de Campinas (RMC) a partir da perspectiva dos desastres socialmente construídos. Seria uma crise de disponibilidade de água, de demanda ou de gestão desse recurso? Para auxiliar nessa discussão, foram utilizados dados coletados de entrevistas semiestruturadas realizadas junto a atores envolvidos com a gestão dos recursos hídricos na RMC. 


\section{A Região Metropolitana de Campinas e a escassez hídrica}

A Região Metropolitana de Campinas (RMC) criada pela lei complementar estadual n. 870, de 19 de junho de 2000, é formada por 20 municípios, apresentando 3,8 mil $\mathrm{Km}^{2}$ de área, com uma população de 2.797.137 habitantes (IBGE, 2011). Encontra-se inserida em um contexto de conflitos pela água envolvendo o Sistema Cantareira. Segundo Carmo e Hogan (2006), a questão dos recursos hídricos é crucial para a RMC desde a década de 1970, em função da reversão de água para o abastecimento de outra região, a Região Metropolitana de São Paulo (RMSP) através do Sistema Cantareira. Destaca-se, também, que é uma região marcada pela preocupação com a falta de água para abastecimento, intensificada na estação seca, entre os meses de maio e setembro.

o Sistema Cantareira foi afetado diretamente pela falta de chuva no período considerado. A região Sudeste começou a ser atingida pela estiagem prolongada no final de 2013, estendendo-se até o final de 2015, quando o regime de chuvas para a região começou a demonstrar indícios de normalização. As chuvas de 2014 foram atípicas na região Sudeste, sendo consideradas um evento de "seca" e raro para a região, com índices pluviométricos entre os piores já registrados em 50 anos (ANA, 2015). Na região Sudeste, a recuperação dos níveis dos reservatórios foi influenciada pelos baixos índices pluviométricos da região.

Os reservatórios do Sistema Cantareira, que abastecem a RMSP e a RMC, acumulam água na estação chuvosa (entre os meses de outubro a março), garantido o abastecimento no período de estiagem. Contudo, o ano de 2013 foi diferente, apresentando, no período de outubro de 2013 a março de 2014, chuvas abaixo da média climatológica (Figura 1), resultando vazões naturais afluentes excepcionalmente baixas, contribuindo, assim, para que os reservatórios não recebessem o volume de água esperado para essa época do ano (Cemaden, 2015).

A falta de chuvas ocorreu de maneira generalizada no estado de São Paulo, atingindo regiões importantes para o armazenamento de água para o Sistema Cantareira, nas bacias dos rios Piracicaba, Capivari e Jundiaí (Bacias PCJ), nas quais se localiza a RMC. Em 2014, conforme mostra a Figura 2, a precipitação acumulada nos municípios onde existiam postos pluviométricos do Ciiagro/Sala de Situação PCJ, ficou abaixo da média anual. Dos 12 municípios que o Sistema Cantareira abrange, cinco apresentam posto pluviométrico: Extrema, Bragança Paulista, Nazaré Paulista, Piracaia e Vargem. Todos esses municípios apresentaram precipitação acumulada abaixo da média anual, no entanto, Extrema (MG) apresentou a menor diferença, enquanto Piracaia foi o município com menor índice pluviométrico de toda a bacia e com maior diferença entre a precipitação acumulada e a média anual (CBH-PCJ, 2015).

A partir do cenário considerado, enfatiza-se que é inegável a existência de baixos índices pluviométricos. No entanto, estes não devem ser analisados de forma isolada. Segundo a ANA (2015), a redução dos índices pluviométricos na região Sudeste prejudicou de forma significativa a oferta de água para o abastecimento público. Contudo, o mesmo relatório afirma que as causas da escassez hídrica do Sudeste não podem ser reduzidas aos menores 
Figura 1 - Precipitação mensal na bacia do Sistema Cantareira,

para o período de outubro de 2012 a setembro de 2015

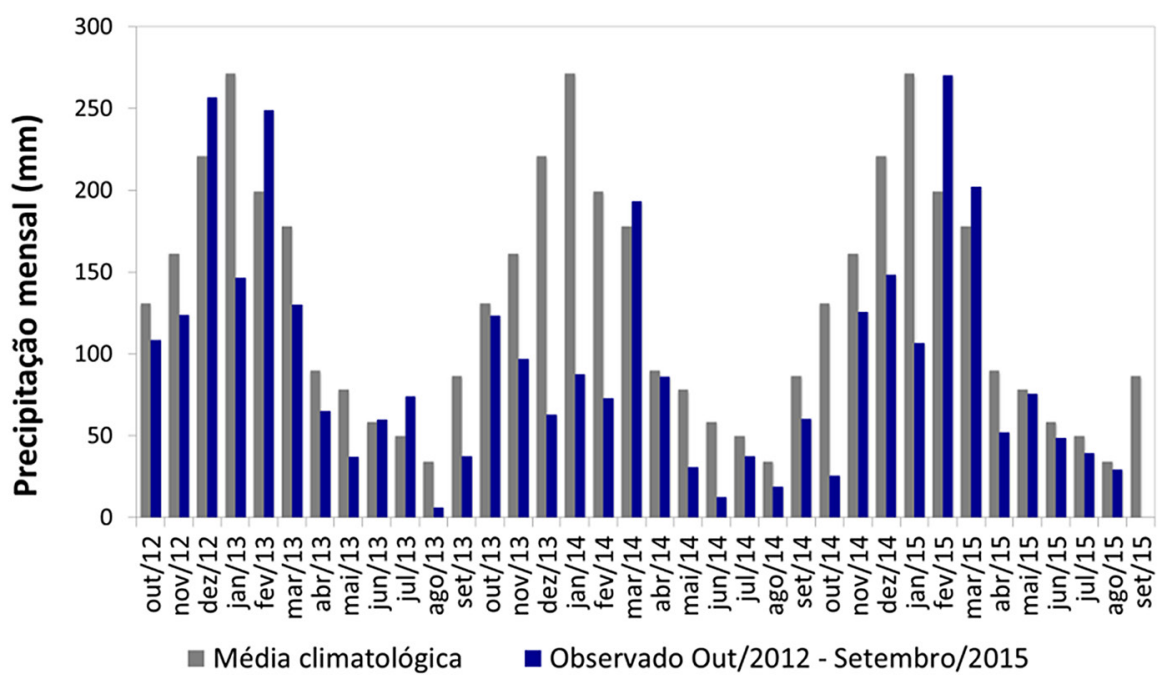

Fonte: figura retirada de Cemaden (2015).

Figura 2 - Precipitação acumulada e média anual dos municípios das Bacias PCJ dos postos pluviométricos, em 2014

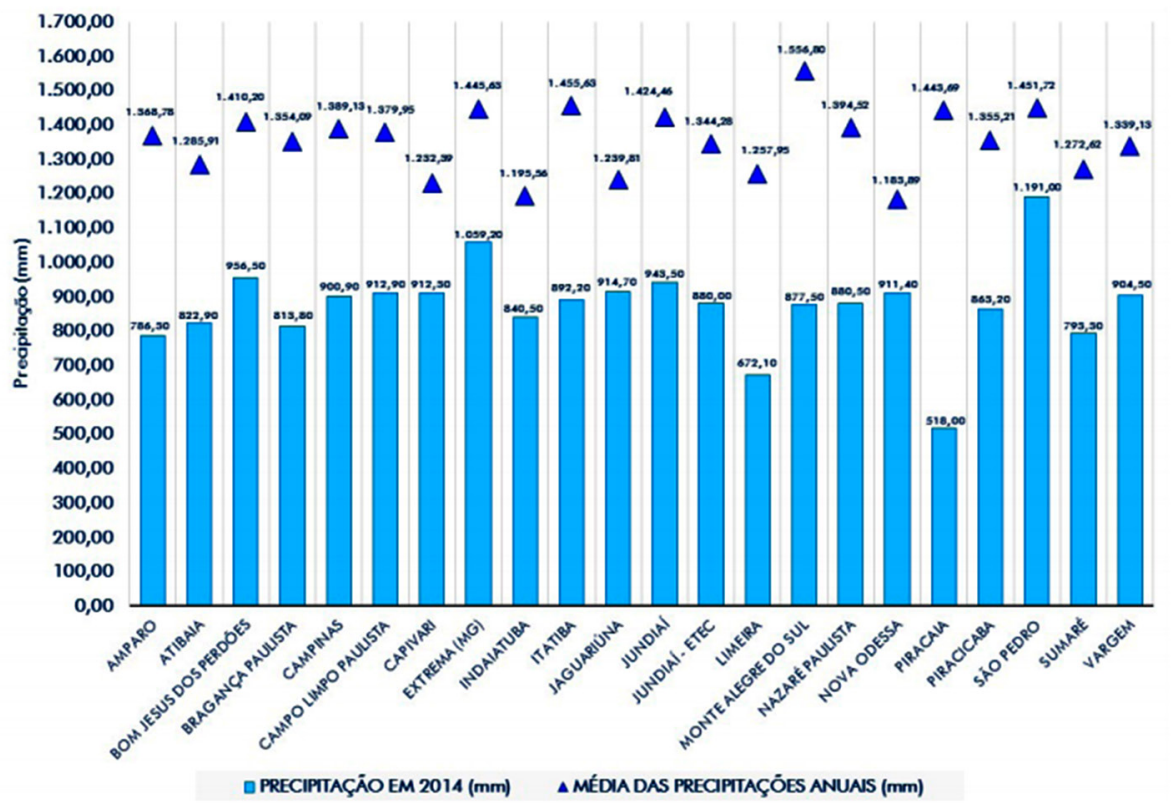

Fonte: figura retirada do Relatório de situação de recursos hídricos (CBH-PCJ, 2015, p. 48). 
volumes pluviométricos, indicando outros fatores, tais como a gestão da demanda e a garantia de oferta.

Com relação à disponibilidade do recurso hídrico, este pode se configurar em situação de escassez mesmo em áreas sem problemas de volume de água. Os tipos de consumo da água se dividem em consuntivo e não consuntivo. 0 uso consuntivo é dividido em três principais grupos: uso urbano, uso industrial e uso para irrigação. Esse tipo de uso implica perdas de volume relacionado ao que é retirado do curso d'água. Já os usos não consuntivos não implicam perda, ao contrário dos usos consuntivos. Dentre os usos não consuntivos, encontram-se geração de energia, navegação, aquicultura, recreação e lazer, usos ecológicos. 0 problema mais recorrente é o conflito existente entre os vários tipos de uso, relacionados com diversos atores sociais e econômicos com específicos interesses de demanda sobre os recursos hídricos (Carmo, 2001).

Destacando as Bacias dos rios PCJ, nas quais a RMC está localizada, segundo o Relatório de Situação dos Recursos Hídricos - 2015 das Bacias dos rios PCJ (CBH-PCJ, 2015), há predominância dos usos de água de fontes superficiais em relação aos usos subterrâneos e também o uso da água para fins de abastecimento público, que consiste em uma característica particular da região diante das características do País. No entanto, o Relatório ainda destaca os usos para fins industriais e a subestimação dos valores de uso de água para fins agrícolas.

Ao considerar apenas a RMC, foi possível analisar que o maior uso da região está relacionado com os usos urbanos $(64,59 \%)$, seguido dos usos industriais (23,71\%). 0 uso de água para fins rurais consiste em apenas 9,24\% dos usos totais. Entretanto, ao analisar os diferentes usos para cada município que compõe a RMC, observaram-se diferenciais importantes nos usos prioritários para cada município. $A$ maior parte dos municípios (total de 9 municípios) apresenta percentual do uso urbano predominante em relação ao uso total, em 2014 (Tabela 1). Os municípios são: Artur Nogueira, Campinas, Engenheiro Coelho, Indaiatuba, Morungaba, Nova Odessa, Santa Bárbara d'Oeste (município com maior demanda urbana em relação ao uso total, de 94,92\%), Valinhos e Vinhedo. Em seguida, sete municípios apresentam uso industrial superior aos demais usos: Americana, Cosmópolis, Hortolândia, Itatiba, Paulínia, Pedreira (município com maior uso industrial em relação ao uso total, de $82,57 \%$ ) e Sumaré. Por fim, quatro municípios apresentam uso rural maior que os usos urbano e industrial: Holambra (município com maior uso rural em relação ao uso total, de $80,52 \%$ ), Jaguariúna, Monte Mor e Santo Antônio de Posse.

Os municípios da RMC apresentam uma demanda de água diversificada, mas há predominância do uso urbano (devido ao grau de urbanização de 97,43\% para a RMC), seguida do uso industrial (por ser considerada uma região altamente industrializada e de importância econômica). Em suma, a região Sudeste apresenta uma alta concentração populacional, com taxas de urbanização elevadas e pouca disponibilidade hídrica, quando comparada a outras regiões hidrográficas. No entanto, como foi observado na RMC, há que se considerar os diferentes usos por água (urbano, industrial e rural), bem como os padrões de consumo de cada município e a sua relação com outros fatores. 
Tabela 1 - Usos total e percentual de demandas urbana, industrial e rural em relação ao uso total, segundo os municípios da Região Metropolitana de Campinas, em 2014

\begin{tabular}{|c|c|c|c|c|c|}
\hline \multirow[b]{2}{*}{ Municípios } & \multicolumn{5}{|c|}{ \% em relação ao uso total } \\
\hline & $\begin{array}{l}\text { Uso total } \\
\qquad\left(\mathrm{m}^{3} / \mathrm{s}\right)\end{array}$ & Uso urbano & Uso industrial & Uso rural & Outros usos \\
\hline Região Metropolitana de Campinas & 6,823 & 64,59 & 23,71 & 9,24 & 2,47 \\
\hline Americana & 0,193 & 19,29 & 76,77 & 2,68 & 1,25 \\
\hline Artur Nogueira & 0,234 & 58,02 & 12,87 & 28,39 & 0,73 \\
\hline Campinas & 0,792 & 68,06 & 17,11 & 8,15 & 6,68 \\
\hline Cosmópolis & 0,559 & 41,51 & 56,32 & 2,17 & 0,01 \\
\hline Engenheiro Coelho & 0,117 & 45,58 & 31,99 & 21,55 & 0,89 \\
\hline Holambra & 0,072 & 9,07 & 5,03 & 80,52 & 5,38 \\
\hline Hortolândia & 0,099 & 13,06 & 58,12 & 27,34 & 1,48 \\
\hline Indaiatuba & 0,968 & 91,64 & 3,27 & 3,29 & 1,81 \\
\hline Itatiba & 0,259 & 33,87 & 47,28 & 13,73 & 5,12 \\
\hline Jaguariúna & 0,085 & 25,71 & 34,84 & 35,19 & 4,26 \\
\hline Monte Mor & 0,083 & 34,76 & 21,48 & 43,76 & 0,00 \\
\hline Morungaba & 0,058 & 60,39 & 17,69 & 13,51 & 8,41 \\
\hline Nova Odessa & 0,341 & 55,13 & 43,83 & 1,04 & 0,00 \\
\hline Paulínia & 0,108 & 16,23 & 38,29 & 12,13 & 33,35 \\
\hline Pedreira & 0,068 & 13,57 & 82,57 & 1,35 & 2,51 \\
\hline Santa Bárbara d'Oeste & 1,015 & 94,92 & 4,95 & 0,13 & 0,00 \\
\hline Santo Antônio de Posse & 0,245 & 27,22 & 8,77 & 59,97 & 4,04 \\
\hline Sumaré & 0,174 & 14,09 & 57,54 & 25,00 & 3,37 \\
\hline Valinhos & 0,666 & 70,37 & 25,84 & 2,02 & 1,77 \\
\hline Vinhedo & 0,686 & 86,15 & 12,72 & 1,09 & 0,04 \\
\hline
\end{tabular}

Fonte: CBH PCJ (2015).

A lei federal 9.433/1997, que instituiu a Política Nacional de Recursos Hídricos, foi um marco importante para a questão dos recursos hídricos. Um dos seus fundamentos se destaca em relação ao uso prioritário e ao uso múltiplo das águas (Silva e Pruski, 2000): a essa lei parte do princípio de que "a gestão dos recursos hídricos deve sempre proporcionar o uso múltiplo das águas", do art. $1^{\circ}$, IV. Mas em "situações de escassez, o uso prioritário dos recursos hídricos é o consumo humano e a dessedentação dos animais", do art. $1^{\circ}$, III. Uma vez que haja a escassez, compete ao órgão público federal ou estadual, responsável pela outorga, suspender parcial ou totalmente as outorgas que prejudiquem os usos prioritários. 
Dessa forma, em um dado contexto de escassez hídrica, os conflitos existentes entre os vários tipos de uso podem ser acirrados, evidenciando a atuação de diferentes atores sociais e econômicos. Esses diferentes atores, com interesses diversos de demanda sobre a água, levam-nos a questionar a maneira como se encontram organizados, diante do modelo de gestão dos recursos hídricos no País, e sua percepção em relação à escassez hídrica ocorrida no período considerado.

\section{A escassez hídrica na RMC enquanto um desastre socialmente construído}

A falta de chuvas e a grande demanda por água influenciaram negativamente a disponibilidade hídrica na região Sudeste, especificamente na RMC. Contudo, não se deve reduzir a causalidade da escassez hídrica a uma crise de disponibilidade (baixos índices pluviométricos para ao período) e demandas (diferentes tipos de usos e suas demandas), exclusivamente. Há que se considerar também a crise de gestão dos recursos hídricos, ou uma crise de governança segundo vários autores (IDS, 2014; ANA, 2015; Jacobi, Cibim e Leão, 2015; Fracalanza e Freire, 2016; Jacobi, Cibim e Souza, 2016).

Uma vez que cenários de escassez de água já estão instalados nas regiões metropolitanas, como saber que esse cenário passou a se constituir como um desastre? Parte-se da premissa de que nem todas as manifestações da natureza, como a chuva, o terremoto e a seca, causam necessariamente um desastre "natural". Este só se configura assim se houver uma correlação com pessoas. Ou seja, quando a população é atingida por esses fenômenos naturais que ocasionam perdas de moradia e de vida (Romero e Maskrey, 1993).

Os desastres são amplamente discutidos pela literatura desde o início do século XX, com intensificação das pesquisas sobre desastres após a Segunda Guerra Mundial, conforme apresentado por Dynes e Drabek (1994) e por Quarantelli e Dynes (1977). No entanto, esses estudos consideram o desastre um evento pontual. Segundo Lavell Thomas e Franco (1996), tratar o desastre como evento é posicioná-lo como imprevisível, ingovernável e inevitável, resultando em estudos com foco na prevenção e previsibilidade dos desastres, uma vez que os eventos físicos foram considerados os principais responsáveis dos desastres e por serem considerados anormais e imprevisíveis. Essa mesma visão do desastre como inevitável e incontrolável apresenta a questão da organização da sociedade em função do enfrentamento do desastre e a forma de conduzi-la ao seu estado de "normalidade" (Lavell Thomas e Franco, 1996).

0 caráter pontual utilizado para a definição do desastre engessa o seu entendimento como um processo. Diante desse cenário, não há discussões sobre as relações sociais que potencializam a vulnerabilidade das pessoas que residem em área de risco (Valencio, 2009). Para elucidar o desastre como processo, parte-se da premissa de que os desastres não são naturais. As chuvas e a seca não matam. É a partir dessas afirmações que se discute que fenômenos naturais são diferentes dos desastres. Este último só ocorre se houver interação com a população. Essa perspectiva torna visíveis a estrutura social existente, as injustiças sociais 
e os diferentes graus de exposição aos perigos (Valencio, 2014).

Cabe, então, discutir e definir os desastres baseados na abordagem social, cujos estudos têm início na década de 1940 e ganham força e estrutura a partir de 1960.0 pioneiro é Charles Fritz, que introduz o conceito de desastre socialmente construído em 1961. Em seguida, ganha espaço a corrente teórica norte-americana, tendo, como um dos representantes expressivos, Enrico Quarantelli, cuja obra $O$ que é um desastre? (1998) representa um marco importante para a abordagem social. Essa obra indica que o desastre, a partir da abordagem social, pode ser configurado como um processo. Contudo, essa corrente é marcada por um enfoque próprio da sociologia norte-americana e seus estudos empíricos (Maskrey, 1993). Na América Latina, os estudos sobre a abordagem social dos desastres ganham destaque no final da década de 1980 e são concentrados pela Red de Estudios Sociales en Prevención de Desastres en América Latina (LA RED), formada em 1992. Destacam-se, também, os estudos realizados no Brasil, especificamente do Núcleo de Estudos e Pesquisas Sociais em Desastres (Neped/Ufscar).

Valencio (2013) enfatiza três aspectos que devem ser considerados no estudo dos desastres sob a abordagem sociológica:

(1) o cerne do desastre é o meio social, o conjunto complexo de sujeitos e forças sociais atuantes; (2) um desastre pode ser descrito como um acontecimento social trágico e pontual sem que, com isso, seja preciso sonegar sua definição como um tipo de crise crônica na esfera social, ou seja, é possível convergir analiticamente situação e processo; por fim, (3) devido às características transescalares dos sujeitos e das relações sociais envolvidas, os desastres podem mesclar situações rotineiras e não rotineiras. ( p. 11)

Ao discutir a aproximação da abordagem dos desastres e das ciências sociais, verifica-se que, ao engessar o conceito de desastre como um evento pontual, as suas causas não são relacionadas (Lavell Thomas, 1993). Dessa forma, o desastre socialmente construído pode ser entendido como:

[...] una ocasión de crisis o stress social, observable en el tiempo y el espacio, en que sociedades o sus componentes (comunidades, regiones, etc.) sufren daños o perdidas físicas y alteraciones en su funcionamiento rutinario. Tanto las causas como las consecuencias de los desastres son producto de procesos sociales que existen en el interior de la sociedad. (Ibid., p. 120)

Considerando, então, os desastres como situação e processo, simultaneamente, destaca-se que tanto a descrição como a análise dos desastres não podem ser resumidas aos objetos no território, mas devem considerar as relações sociais em si, cujo produto é o observável espacialmente (Valencio, 2013).

Para entender a escassez hídrica ocorrida na RMC como um desastre socialmente construído, foi necessário considerar os processos históricos referentes à gestão dos recursos hídricos na região metropolitana, questões relacionadas a produção e reprodução de condições desiguais de acesso à água, além de questões culturais referentes ao consumo de água. ${ }^{2}$ Isso significa que a questão da escassez hídrica enquanto um desastre socialmente construído requer uma leitura multidimensional, multiescalar e integradora. Para este trabalho em 
questão, uma dimensão dessas dimensões foi escolhida e consiste na percepção de diferentes atores institucionais e sociais, envolvidos com a gestão dos recursos hídricos.

A percepção de diferentes atores institucionais e sociais permite verificar que outros elementos, além dos números de disponibilidade e demanda, precisam ser considerados. Parte-se da premissa de que considerar a escassez hídrica, enquanto um evento pontual ou um processo, pode influenciar na percepção dos gestores, que também pode ser influenciada pelo modelo de gestão dos recursos hídricos vigente e, por fim, pode resultar em diferentes respostas à situação enfrentada por parte desses atores.

\section{A percepção dos atores sociais envolvidos no processo de gestão dos recursos hídricos na RMC}

Para esta análise, foram realizadas entrevistas semiestruturadas com atores de diversos setores da gestão dos recursos hídricos, sobre sua percepção da escassez hídrica e, especificamente, sobre a situação ocorrida na
RMC, entre 2013 e 2015. Para isso, estabeleceu-se contato com o Comitê de Bacias dos rios Piracicaba, Capivari e Jundiaí, buscando viabilizar as entrevistas com os atores relacionados. Em novembro de 2016, foram realizadas 13 entrevistas, que, juntas, somaram 3 horas e 27 minutos. Como os entrevistados não tiveram seus nomes revelados, eles serão identificados por números (de 1 a 13) e o setor que eles representam no Comitê de Bacias, como mostra o Quadro 1.

As entrevistas semiestruturadas fizeram parte do projeto "As percepções sobre a grave escassez hídrica no município de Campinas, entre 2013 e 2015", enviado ao Comitê de Ética em Pesquisa (CEP) da Universidade Estadual de Campinas (Unicamp), identificado pelo Certificado de Apresentação para Apreciação Ética (CAAE) número 54023216.9.0000.5404.

Ao serem questionados sobre a análise da escassez hídrica ocorrida entre 2013 e 2015 e se esta poderia ser considerada um desastre, a maior parte dos atores entrevistados respondeu que não se trata de um desastre. Termos como "evento climático", "estiagem crítica", "mudanças climáticas", "ano atípico", "fenômeno natural" foram citados como resumo do que a escassez hídrica representava para esses atores:

Quadro 1 - Entrevistados e setor que representam

\begin{tabular}{|l|l|}
\hline \multicolumn{1}{|c|}{ Entrevistados } & \multicolumn{1}{c|}{ Setor que representa } \\
\hline Entrevistados 1 e 4 & Representante dos órgãos do governo \\
Entrevistados 2, 3, 5, 9, 10 e 12 & Representante dos usuários \\
Entrevistado 6 & Representante dos municípios \\
Entrevistados 7, 8, 11 e 13 & Representante das organizações civis \\
\hline
\end{tabular}

Fonte: elaboração da autora. 
[...] eu não entendo que seja um desastre. Porque o desastre que eu entendo é uma situação como a de Mariana (citando o desastre ocorrido com o rompimento de barragem de rejeitos de minérios, em Mariana, Minas Gerais, em 2015), uma situação onde tem famílias que morrem, que tem uma situação muito mais crítica. Não considero um desastre, mas considero um ponto de atenção muito importante a ser considerado em todos os planejamentos que poderão ocorrer daqui por diante. (Entrevistado 3, Representante dos usuários)

A gente teve um ano atípico do ponto de vista climatológico. Sem dúvida. Bem atípico. Ao longo dos anos faltou talvez gestão. Gestão macro, mesmo os comitês por mais que tenham atuado com qualidade, mas talvez não consigam ainda permear pela sociedade, pela área política. (Entrevistado 9, Representante dos usuários)

Em termos de gestão, para nós, foi uma surpresa total e foi realmente, não digo um desastre, mas foi um sinal de que a gente tem que melhorar muito nosso sistema de alerta, nosso sistema de reservação, de acumulação de água. Que nossos depósitos de águas estão muito aquém daqueles necessários e que nossas captações de abastecimento público que estão diretamente localizadas nos cursos d'água são muito susceptíveis desses fatos mais críticos, os fenômenos extremos da natureza. E que a população não deve estar sujeita a esse nível de risco, de desabastecimento.(Entrevistado 4, Representante dos órgãos do governo)

A crise hídrica foi um fenômeno natural, em que algum ponto de vista nós estávamos preparados para lidar com ele e, em outros, nós fomos surpreendidos. Foi surpreendente pela extensão temporal da crise. (Entrevistado 10, Representante dos usuários)
Eu resumiria em uma palavra: ela é fruto dos eventos climáticos extremos. Já tinham sido avisados desde 2000, que iriam acontecer, pela Cúpula do Clima. Só que, quando aconteceu, principalmente o governo do estado de São Paulo e a Sabesp não estavam preparados. 0 sistema da grande São Paulo não estava interligado, não tinha reservatório suficiente, não tinha nenhum plano estratégico estabelecido. Aí eles secaram o Cantareira para garantir o abastecimento da capital (São Paulo). (Entrevistado 13, Representante das organizações civis)

Foi possível observar que os atores entrevistados não consideraram a situação ocorrida como um desastre, e sim como uma eventualidade, ocorrida de forma inesperada e que pode ter sido tratada de forma ingovernável e inevitável, distanciando-se, assim, da perspectiva de um desastre, desconsiderando as relações sociais construídas historicamente e verificadas em um momento de desastre. Sendo assim, outro aspecto desconsiderado nessa escassez hídrica foi a construção histórica dos modelos de gestão dos recursos hídricos, principalmente em relação à participação da população no processo de gestão dos recursos hídricos.

A lei estadual n. 7.663, de 30 de dezembro de 1991, ${ }^{3}$ que estabelece normas de orientação à Política Estadual de Recursos Hídricos bem como ao Sistema Integrado de Gerenciamento de Recursos Hídricos no estado de São Paulo, e a lei n. 9.433, de 8 de janeiro de $1997,{ }^{4}$ que instituiu a Política Nacional de Recursos Hídricos e criou o Sistema Nacional de Gerenciamento de Recursos Hídricos, consistiram em um avanço em termos de governança, por promover a participação de diferentes atores na gestão dos recursos hídricos (Jacobi, 
Cibim e Leão, 2015). Um exemplo da participação de diferentes atores concretiza-se com a criação dos Comitês de Bacias Hidrográficas (CBHs) como instâncias de gestão regionais. 0 primeiro $\mathrm{CBH}$ instalado no estado de São Paulo foi o Comitê das Bacias Hidrográficas dos rios Piracicaba, Capivari e Jundiaí (CBH-PCJ), em 1993. Nas Bacias PCJ, há uma articulação permanente entre três comitês: o CBH-PCJ, 0 PCJ Federal (instituído pela lei n. 9433/97) e o CBH dos rios Piracicaba e Jaguari (CBH-PJ, instituído pela lei estadual de Minas Gerais n. 13199/1999). Os comitês PCJ visam promover o gerenciamento dos recursos hídricos em sua área de atuação de forma descentralizada, participativa e integrada em relação aos demais recursos naturais, sem dissociação dos aspectos quantitativos e qualitativos e das peculiaridades das bacias hidrográficas. ${ }^{5}$

Segundo Castellano e Barbi (2009), nos últimos anos, a atuação em termos cooperativos entre o Consórcio e os Comitês PCJ ante a gestão compartilhada dos recursos hídricos, resultou em importantes instrumentos de gestão nas bacias do PCJ, dentre eles as outorgas e a implementação do sistema de cobrança pelo uso dos recursos hídricos.

Os avanços possibilitados pela lei estadual n. 7.663/1991 e pela lei 9.433/1997, ao considerar a gestão dos recursos hídricos de forma integrada e descentralizada, instituindo a participação dos usuários e das comunidades, no momento de escassez hídrica, tornaram-se imperceptíveis. Segundo Jacobi, Cibim e Leão (2015), o envolvimento da comunidade ficou limitado apenas aos Comitês, indicando uma fragilidade nas relações entre os diferentes atores envolvidos (governamentais, empresariais e usuários), e a pequena participação de fato da sociedade civil nos Comitês. Outro grande problema apresentado pelos autores citados foi a centralização de poder e decisão em um único ator no momento de escassez hídrica, desconsiderando a construção política integrada e descentralizada vigente:

Quando observamos a atuação do governo do estado de São Paulo diante da crise hídrica, vemos que a posição tomada é absolutamente contrária ao que se espera para obter-se uma boa governança da água. Com um discurso absolutamente técnico e centralizador, o estado de São Paulo afasta qualquer integração com a população, podando o envolvimento da sociedade na discussão, tanto da causa da crise, como também das possíveis soluções para o enfrentamento do problema. (Ibid., p. 36)

Além da falta de diálogo entre os diferentes atores envolvidos no processo desencadeado pela escassez hídrica, outro ponto preocupante foi a falta de transparência e de comunicação com a população. Exemplo disso foi a intervenção do Ministério Público do estado de São Paulo ${ }^{6}$ realizada junto à Sabesp, responsável por disponibilizar os dados de volume armazenado no Sistema Cantareira. Segundo o Ministério Público, os cálculos sobre o volume armazenado estavam incorretos, por considerar apenas o volume útil do sistema (982 milhões de $\mathrm{m}^{3}$ de água), e o novo cálculo deveria considerar, além do volume útil, também as reservas técnicas (287,5 milhões de $\mathrm{m}^{3}$ ), obtendo-se, assim, o volume total do sistema. Ou seja, o volume armazenado divulgado até então estava ocultando o real cenário de armazenamento do Sistema Cantareira para a população. Os questionamentos seguiram, resultando em 16 de abril de 2015 uma nova 
liminar, cedida pelo juiz Evandro Carlos de Oliveira, solicitada pelo Ministério Público, exigindo que a Sabesp divulgasse a porcentagem "negativa" do Cantareira. Dessa forma, passaria a considerar o volume morto como um agravante e uma situação atípica, ou seja, é um volume que não deveria ser utilizado, passando a ser entendido como um empréstimo. A situação de normalidade só voltaria quando a captação de água fosse exclusivamente do volume útil.

Segundo Empinotti, Jacobi e Fracalanza (2016), as informações sobre a escassez hídrica para a população da RMSP limitaram-se ao volume dos reservatórios de água do Sistema Cantareira. Foi possível observar que as informações foram pouco transparentes e necessitaram de intervenções do Ministério Público para que se tornassem claras e objetivas ao público. A comunicação sobre a escassez hídrica foi lenta, tardia e pouco transparente. Dessa forma:

Ao negar o problema e não disponibilizar informações, o governo de São Paulo impôs uma realidade fabricada. Assim, a não disponibilização de informações, combinada à irrelevância dos dados apresentados, impossibilitou que a população atingida pela falta de água tivesse $a$ informação necessária para lidar com essa situação. Dessa forma, o governo de São Paulo se tornou o principal tomador de decisão a partir de uma realidade embasada em informações disponibilizadas de baixa relevância e pelo controle total das ações. (Ibid., pp. 70-71)

0 entrevistado 13, representante das organizações civis também concorda sobre a falta de informação ou, em suas palavras, "informação enganosa":

Houve omissão dos órgãos gestores oficiais, e eles se omitiram quanto a oferecer, à comunidade, a realidade. Todos os depoimentos do governo do estado (de São Paulo) eram de que estava tudo bem, que não haveria racionamento, mas não estava tudo bem, tanto é que houve problemas sérios de racionamento. Houve foi informação enganosa. Tudo bem que eles não quiseram causar pânico, mas uma coisa é você não causar pânico, outra coisa é você deixar de organizar a sociedade. Você tem como informar o que está ocorrendo de fato, usando palavras que não seja o volume morto, ou seja, usando palavras adequadas e engajar a sociedade para uma reação. (Entrevistado 13, Representante das organizações civis)

A maior parte dos entrevistados afirmou que não seria possível atribuir responsabilidades pela escassez hídrica, enquanto outros indicavam a gestão, de forma geral, bem como a população, como responsáveis. Já o entrevistado 10 absteve-se de indicar um responsável, por entender que se tratava de um desastre natural, corroborando o que Lavell Thomas e Franco (1996) afirmam quanto ao caráter pontual do desastre como um evento, ou seja, o desastre é tratado como imprevisível, ingovernável e inevitável. A população também foi apontada como uma das responsáveis pela escassez hídrica, pelos entrevistados 2 e 6.0 entrevistado 6, porém, destaca que a falta de conscientização da população e o desperdício da água são os principais responsáveis. Os principais comentários sobre a responsabilidade da escassez hídrica estão dispostos no Quadro 2. 


\section{Quaadro 2 - Percepção dos atores sobre a responsabilidade da escassez hídrica}

\begin{tabular}{|c|c|}
\hline $\begin{array}{l}\text { Responsabilidade da escassez hídrica } \\
\text { para os atores }\end{array}$ & Percepção dos atores \\
\hline $\begin{array}{l}\text { Não há responsáveis dada } \\
\text { a naturalidade do evento }\end{array}$ & $\begin{array}{l}\text { Foi um desastre natural. Acho que não dá para atribuir responsabilidade a } \\
\text { ninguém (Entrevistado 10, Representante dos Usuários). }\end{array}$ \\
\hline $\begin{array}{l}\text { Todos são responsáveis, } \\
\text { com foco nos gestores }\end{array}$ & $\begin{array}{l}\text { Eu sinto que todos nós somos responsáveis, porque a gente, bem ou mal, é } \\
\text { gestor. Então nós tínhamos condição de ter feito uma represa, nós tínhamos } \\
\text { isso no nosso planejamento, mas a gente vai deixando e vai fazendo outras } \\
\text { coisas que acha que tem mais urgência. Então todos falhamos. Eu acho que } \\
\text { a gente tem que reconhecer os erros para poder resolver e mudar um pouco } \\
\text { essa política daqui para frente. Não pode se acomodar. É a hora da gente. } \\
\text { Olha, essa crise foi um marco, mas ela está aí, ela é um fato que está ainda } \\
\text { acontecendo. Então vamos mudar. Não pode falar que resolveu tudo e vamos } \\
\text { voltar ao que era antes. Não. Temos que agir. Falta ação (Entrevistado 12, } \\
\text { Representante dos Usuários). }\end{array}$ \\
\hline $\begin{array}{l}\text { Todos são responsáveis, } \\
\text { com foco nos gestores }\end{array}$ & $\begin{array}{l}\text { Acho que todos são responsáveis. A população, os usuários. Uns mais e outros } \\
\text { menos. Acho que quem tem o poder de decisão, quem tem o poder de gestão, } \\
\text { de governança, lógico são os mais responsáveis, porque eles têm que tomar } \\
\text { essas providências (Entrevistado 6, Representante dos Municípios). }\end{array}$ \\
\hline $\begin{array}{l}\text { Todos são responsáveis, } \\
\text { com foco na população }\end{array}$ & $\begin{array}{l}\text { Sim. Nós. Todos nós somos responsáveis. A partir do momento que entro no } \\
\text { banheiro e fico } 20 \text { minutos lá, eu sou responsável pela crise hídrica. A partir } \\
\text { do momento que a gente está lavando um carro na rua, desperdiçando água } \\
\text { potável, jogando produtos químicos na natureza, somos todos responsáveis } \\
\text { (Entrevistado 2, Representante dos Usuários). }\end{array}$ \\
\hline $\begin{array}{l}\text { Falta de recursos não possibilitou } \\
\text { a execução do planejamento }\end{array}$ & $\begin{array}{l}\text { A Região Metropolitana de São Paulo e as bacias PCJ são as mais planejadas } \\
\text { da América Latina. O planejamento dessas duas bacias ocorre desde a década } \\
\text { de 1994. Nós já temos soluções planejadas para todas as medidas. } 0 \text { que faltou } \\
\text { foi o recurso. Eu não culpo o governo do estado (de São Paulo), eu não culpo } \\
\text { os governos municipais, porque o planejamento sempre existiu. Não faltou } \\
\text { planejamento, faltou recurso para execução (Entrevistado 13, Representante } \\
\text { das Organizações Civis). }\end{array}$ \\
\hline
\end{tabular}

Fonte: elaboração da autora. Dados obtidos a partir das entrevistas semiestruturadas (2016).

Durante a escassez hídrica, observou-se também o acirramento de conflitos que já existiam, como foi o caso da renovação da outorga do Sistema Cantareira, que venceria em agosto de 2014, mas foi estendida por duas vezes (até outubro de 2015, por meio da resolução conjunta ANA-DAEE n. 910/2014), e a segunda até maio de 2017, por meio da resolução conjunta
ANA-DAEE n. 1.200/2015), ${ }^{7}$ devido à "situação de excepcionalidade da baixa disponibilidade hídrica", conforme a resolução n. 910/2014. A renovação da outorga já se estende como conflito desde 2004. Conflito regional pela água, envolvendo a RMC e a RMSP, a renovação da outorga do Sistema Cantareira em 2004 garantiu uma perspectiva de maiores volumes de 
água destinados às bacias dos rios $\mathrm{PCJ}$ (Carmo e Hogan, 2006). Em 2004, o DAEE concedeu a outorga do Sistema Cantareira à Sabesp, cujo prazo foi expirado em agosto de $2014 .^{8}$

Em meio às discussões para a renovação da outorga, uma Ação Civil Pública ${ }^{9}$ foi movida pelos promotores Alexandra Facciolli Martins (Gaema-PCJ Piracicaba), Geraldo Navarro Cabañas (Gaema-PCJ Campinas), Ivan Carneiro Castanheiro (Gaema-PCJ Piracicaba), Rodrigo Sanches Garcia (Gaema-PCJ Campinas) e pelo procurador da República de Piracicaba Leandro Zedes Lares Fernandes, em 30 de setembro de 2014, indicando que havia uma gestão de risco do Sistema Cantareira por parte da Sabesp.

Segundo essa Ação, as "Curvas de Aversão a Risco" (CAR), que estabelecem as vazões de retirada (reversão de $31 \mathrm{~m}^{3} / \mathrm{s}$ para a RMSP e de $5 \mathrm{~m}^{3} / \mathrm{s}$ para as Bacias P(J), ${ }^{10}$ de acordo com a quantidade acumulada para as bacias PCJ e para a bacia do Alto Tietê, consistem em uma forma de segurança hídrica, por determinar uma vazão-limite de retirada de água sem comprometer o sistema nos 24 meses seguintes, podendo manter uma reserva hídrica. No entanto, a Sabesp não respeitou os limites de vazão de retirada em plena escassez hídrica, retirando mais água do que estabelecido pelas CAR para a RMSP (segundo o documento da Ação Civil Pública, o limite de retirada, em março de 2014, segundo as CAR, deveria ser abaixo de $27 \mathrm{~m}^{3} / \mathrm{s}$, considerando a vazão para a RMSP e para a Bacia PCJ. No entanto, a vazão autorizada para o referido mês foi de $30,90 \mathrm{~m}^{3} / \mathrm{s}$ ). As vazões de retiradas acima do permitido foram justificadas pelo "Banco de Águas", uma "poupança de água" que a RMSP e a Bacia do Rio Piracicaba podem utilizar em períodos secos mais críticos. Como resultado dessa ação civil, a resolução conjunta ANA/DAEE n. 335/2014 suspendeu a utilização dos Bancos de Água, e os limites de vazão de retirada foram estabelecidos em resoluções conjuntas, mês a mês.

De acordo com determinados atores entrevistados, o conflito pelas águas existente entre a RMSP e as bacias do PCJ, na figura do Sistema Cantareira, é o maior existente hoje no âmbito das Bacias PCJ. Esses entrevistados lembraram que, ao transpor água para a bacia do Alto Tietê, as Bacias PCJ não podem se isolar e precisam pensar conjuntamente no planejamento do Sistema. No entanto, no momento da escassez hídrica, o planejamento falhou, segundo o Entrevistado 13, representante das organizações civis e o Entrevistado 9, representante dos usuários:

Se quem libera a vazão é o governo estadual (de São Paulo) e a Sabesp, e as vazões não estão sendo liberadas, quem é que não está cumprindo? É o DAEE e a Sabesp. O governo do estado não respeitou as medidas provisórias implantadas pelos organismos gestores. Ele respeitou rigorosamente para São Paulo. Para São Paulo ele não mandou nenhuma gota a menos. Mas aqui para o interior faltou. [...] tentamos usar até a força política, 0 que eu acho um absurdo, porque se eu tenho dois órgãos gestores estabelecendo medidas de restrição, e uma região é atendida, a outra também tem que ser atendida, porque senão a credibilidade do sistema deixa de existir. (Entrevistado 13, Representante das organizações civis)

Na verdade, não é falha de gestão. É a disputa entre a grande São Paulo, Sabesp, sem posição partidária, só um fato, e a nossa região. Houve essa disputa, onde a região de Campinas foi um pouco prejudicada. Outro problema que eu vejo na gestão, eu me coloco no lugar do governador 
(do estado de SP São Paulo). Veja bem, como a gente tem o Cantareira, que era a Bacia do Piracicaba que desviou para São Paulo, obra maravilhosa, muito bem-feita. Eu não estou questionando o Cantareira. Só que, por causa desta, nós ficamos umbilicalmente ligados à grande São Paulo. Então, hoje, nós não podemos pensar Campinas isoladamente. Tem que pensar que tem o Sistema Alto Tietê, o Cotia, o Guarapiranga. Então o governador não pode pensar numa obra para Campinas. Tem que pensar numa obra que abasteça as duas regiões. Ao invés de fazer uma barragem em Pedreira ou em Amparo, ele pode fazer uma outra obra na grande São Paulo, de forma que sobra mais água do Cantareira para Campinas. Ele tem que pensar dessa forma, porque ele é governador do estado e não governador da grande São Paulo nem de Campinas. Então tem que respeitar. É o dever dele. (Entrevistado 9, Representante dos usuários)

Outro ponto relacionado às medidas tomadas no momento de escassez hídrica consiste naquelas baseadas na diminuição da demanda urbana. Essas medidas são, a curto prazo, imediatistas e focadas na diminuição do consumo da população, por meio de aumentos tarifários, rodízios/racionamentos, aplicação de bônus/multas e campanhas educativas.

Na RMC, as medidas relacionadas à diminuição de demandas estiveram presentes na maior parte dos municípios. Os reajustes fazem parte das medidas de enfrentamento da crise hídrica. Cita-se, como exemplo, o município de Campinas, que teve sua tarifa de água elevada duas vezes em menos de 12 meses $(11,98 \%$ em fevereiro de 2015 e 15\% em agosto de 2015). A Sanasa (Sociedade de Abastecimento de Água e Saneamento, companhia distribuidora de água em Campinas) alegou "revisão extraordinária" para equilíbrio econômico-financeiro (G1 Campinas e Região, 2015). Mas, segundo o presidente da Sanasa, Arly de Lara Romêo, o reajuste de tarifas está relacionado ao baixo consumo praticado pela população: "Houve uma redução do consumo, e consequentemente resultou no faturamento da empresa. É a necessidade de a empresa manter-se cumprindo com seus compromissos e seus investimentos" (Rossi, 2015). Há que se lembrar que, desde o início da crise hídrica, a Sanasa tem apelado ao consumidor para que economize água.

Com relação aos impactos para a população, o consumo de água já era questionado em 18 de dezembro de 2013, quando o Consórcio PCJ alertava que os níveis de chuva estavam bem abaixo da média. Esse fator, aliado à quantidade de água que entrava no sistema e o que estava sendo retirado para o abastecimento da Grande São Paulo, resultaria em um consumo de toda a água dos reservatórios em 100 dias (Costa, 2014c). 0 ano de 2014 foi marcado por interrupções de fornecimento de água na Região Metropolitana de Campinas (Costa, 2014a e 2014b). Destaca-se o protesto contra a falta de água ocorrido no bairro Santo Antônio, na região dos DICs (Distrito Industrial de Campinas), onde moradores ficaram sem água por vários dias (Sampaio, 2014). Em 2014, o município de Cordeirópolis decretou calamidade pública. Além disso, ao menos cinco municípios decretaram situação de emergência pelo mesmo motivo: Artur Nogueira, Casa Branca, lepê, Tambaú e Valinhos (Marchezi, 2014).

0 agravante mais recente da crise hídrica foi relacionado com a questão da saúde da população. Os casos de diarreia aguda aumentaram em 2014, associados à crise hídrica, 
conforme aponta o Centro de Vigilância Epidemiológica (CVE), órgão da Secretaria Estadual de Saúde. Campinas foi apontada como um dos municípios que apresentaram esse quadro. Segundo o CVE,

a diminuição de pressão, a intermitência do abastecimento, o racionamento, o consumo do volume morto das represas e 0 uso da água de poços e caminhões-pipa, cuja qualidade não é sempre fiscalizada conforme a lei, são as principais causas que podem comprometer a qualidade da água e promover o surgimento de surtos (ocorrência de dois ou mais casos) de diarreia e outras doenças transmissíveis pela água. (Martín, 2015)

No município de Campinas, apesar de o estado de São Paulo decretar a escassez hídrica de forma lenta, houve uma tentativa de oficializar o período crítico em 2014, a partir de uma modificação do decreto ${ }^{11}$ n. 14.802 de 2 de julho de 2004, dispondo sobre a utilização de água para limpeza de calçamentos e passeios públicos residenciais e comerciais existentes no município, em um momento de escassez hídrica, penalizando a população através de autuações caso a determinação não fosse cumprida. Houve ainda o decreto n. 18.251, de 3 de fevereiro de 2014, que estipulou um período excepcional de estiagem, de fevereiro a agosto de 2014, e que também dispunha sobre as infrações e as multas aplicadas àqueles que estivessem desperdiçando água (lavagem de calçamentos e passeios públicos). A questão inerente ao processo de estipulação de multas como forma de punição ao consumidor é a transformação da população em agente fiscalizador, como mostra Semeghini (2014), que afirma que o anúncio da aplicação de multas estimulou a população a fiscalizar.
As campanhas educativas, que deveriam ser construídas ao longo do tempo, também foram caracterizadas como uma medida emergencial, como foi o caso do município de Campinas. A companhia distribuidora de água realizou uma campanha, iniciada em juIho de 2015, que utilizava como simbologia as cores verde (uso sem restrição, com consciência), amarela (momento de cuidado e de alerta para uma possível situação de restrição) e vermelha (possibilidade de restrição no abastecimento, através de rodízio) (Sanasa, 2015). Na ocasião, além da veiculação na mídia, os reservatórios do município foram iluminados com as cores indicativas. No entanto, foi realizada uma investigação, por parte do Ministério Público de São Paulo, para averiguar se a campanha poderia ter induzido o aumento de consumo de água, em um período de estiagem, com a sinalização "verde" por parte da Sanasa, estimulando a retomada do consumo pela população (Cultura Carta Campinas, 2015).

Embora essa campanha tenha sido muito discutida e passível de críticas, é importante observar que Campinas apresenta uma demanda urbana maior que os demais tipos de usos da água. 0 que indica que as ações de comunicação deveriam mesmo focalizar no consumo urbano. Contudo, deve-se atentar ao tipo de comunicação utilizada e às potenciais consequências que foram, de certo modo, subestimadas por parte dos gestores de Campinas.

Ao serem questionados sobre o papel e a responsabilidade da população durante a escassez hídrica ocorrida, a maior parte das respostas dos atores foi resumida ao uso racional, ou seja, a população deveria consumir de forma consciente. No entanto, foi possível 
observar que os entrevistados 12 e 9 buscaram por um enfoque na participação da população.

Cobrar! Eu acho que tem que cobrar. A população fez a parte dela. A população mudou consumo, ficou em cima. Mas ela tem que continuar cobrando porque as prioridades mudam. Agora foi um processo eleitoral, mudam-se os governantes, então os novos governantes têm que entender que isso ai é um problema que está factível de acontecer a qualquer momento. Então a população tem que agir nisso, tem que cobrar os governantes para que isso não seja só um episódio que acabou e não vai acontecer mais. (Entrevistado 12, Representante dos usuários)

A população tem que ser mais bem-informada. A população tem que entender melhor o fenômeno em si. Ela fazer a parte dela, tudo bem, diminuir consumo na casa, mas também participar mais do jogo político. Ir na câmara de vereadores e ver a discussão, para pressionar no sentido positivo. Ela se omite. Diz: "fiz minha parte", mas não basta. Tem que ter mais participação. (Entrevistado 9, Representante dos usuários)

Eu acho que a Sanasa criou uma situação de que se a pessoa usasse a água para lavar carro, para lavar calçada com aquele esguicho hídrico, vassoura hídrica, era multada. Só que tem gente que o dinheiro não tem problema nenhum: "pode me multar que eu vou continuar fazendo". Então, eu acho que a população tem o papel fundamental de que ela tem que usar não só no momento crítico, mas em todos os momentos, a água com parcimônia. Ela não tem que ficar infeliz também: "não posso regar minha plantinha". Não, pode ser feliz, rega sua plantinha, cuida da sua plantinha. Mas usa com cuidado, com consciência. Então acho que a participação da população é fundamental, nessa situação em que ela deve participar do consumo da água com consciência. Porque a ONU fala de 110 I./hab.dia, na grande São Paulo é 368l./hab.dia. Então está muito acima. Campinas, se você considerar residencial, 157 I./hab.dia. Se considerar tudo, residência, serviço, indústria, dá 180 l./hab.dia. Então Campinas já está num patamar um pouco mais avançado no sentido de conscientização da população. Então isso favoreceu e ajudou muito a Sanasa de passar a crise sem essa situação de desespero. (Entrevistado 3, Representante dos usuários)

Como já disse, cabe à população o uso racional, ter em mente que a água "não" é um bem infinito como se propagou até alguns anos atrás. 0 descarte correto de todos os sólidos, seja ele orgânico ou não, contribui para que a restauração ambiental seja acelerada. Cenas de pneus, sofás, garrafas pets, etc. no meio do rio, prejudicando seu fluxo, só mostra que temos muito que aprender e evoluir. (Entrevistado 1, Representante dos órgãos de governo)

Na verdade, é o excesso. A gente é acostumado a não ter limite. Tem que se limitar. Tem que ver quanto eu preciso de água por dia para sobreviver, e manter aquele limite. (Entrevistado 7, Representante das organizações civis)

Foi possível observar que as medidas tomadas a curto prazo estavam voltadas para a diminuição da demanda urbana: o aumento de tarifas de água, aplicação de multas, rodízio/racionamento, campanhas de redução de consumo. Essas medidas seletivas e de caráter imediatista, focadas em apenas um setor de demanda, especificamente no município de Campinas, considerando o momento de escassez hídrica, evidenciaram uma outra questão a ser discutida: qual população foi atingida? 
Tendo em consideração a construção social da escassez hídrica como um desastre, que perpassa pela construção das cidades, ou seja, o processo de produção do espaço urbano tendo como resultado a desigualdade das cidades, capaz de revelar, em um momento de desastre, as vulnerabilidades das populações construídas historicamente (Carmo, 2014), a escassez hídrica ocorrida entre 2013 e 2015 revelou não apenas a desigualdade de acesso à água, mas também a capacidade de resposta diferenciada ao desastre, e até mesmo a ausência de resposta. Segundo Fracalanza e Freire (2015, p. 471):

Assim, cabe observar que, em situações de escassez, é fundamental que as populações sejam orientadas e consideradas igualmente de modo que não sejam prejudicadas em seu acesso à água, de modo a não se estabelecerem conflitos entre os usos da água (por exemplo, industrial e abastecimento doméstico) e de modo a haver uma distribuição mais igualitária da água para populações de modo amplo, não prejudicando o acesso à água por populações de baixa renda.

No entanto, a população desfavorecida economicamente, no momento de escassez hídrica, apresentou uma capacidade de resposta limitada por não ter acesso ao abastecimento adequado (em termos de qualidade e quantidade), por não ter muitas vezes como arcar com um aumento tarifário da água e por não poder comprar água para suprir suas necessidades, que muitas vezes não condizem com 0 padrão de consumo dos que possuem maiores condiç̧ões econômicas. Assim, a capacidade de resposta diminuída ou ausente constitui-se como um caso de injustiça ambiental:
[...] a injustiça ambiental encontra-se no fato de a população que menos contribui com o agravamento dos problemas ambientais decorrentes dos processos de industrialização e de consumo de bens e serviços ser a população que mais sofre com os problemas ambientais decorrentes dos mesmos processos de industrialização e consumo. (Ibid., p. 472)

Foi possível observar que a percepção de grande parte dos atores entrevistados foi de culpabilização da população pelo desperdício e uso irracional da água em um momento em que se deveria economizar. Desconsiderar os diferenciais de vulnerabilidades da população, por parte dos diversos atores envolvidos com a gestão dos recursos hídricos, pode resultar em uma invisibilidade das capacidades de respostas dessa população, bem como da necessidade de medidas de gestão diferenciadas para a população desprovida de condições econômicas.

\section{Considerações finais}

Ao analisar a escassez hídrica ocorrida na Região Metropolitana de Campinas, entre 2013 e 2015, pela perspectiva dos desastres socialmente construídos (Lavell Thomas e Franco, 1996; Valencio, 2013 e 2014), foi possível observar que esse desastre vai além de um evento pontual. Segundo Hannigan (2006), a relação entre natureza e sociedade ocorre de forma dinâmica e sofre com o processo do que o autor chama de improvisação. Perturbações na natureza agem em um determinado instante, influenciando as 
concepções, os discursos e as práticas humanas, resultando em "respostas improvisadas", que acabam por determinar o caráter imediatista das instituições que realizam a gestão dos recursos hídricos.

Foi observado também que, ao analisar o discurso de determinados atores sociais através das entrevistas semiestruturadas, não houve a percepção de um desastre, apenas de um evento extremo, pontual, preocupante, mas que já passou. Ou seja, para esses entrevistados houve uma desconsideração da construção social do desastre, que pode causar certo tensionamento entre as relações da população e gestores. Segundo Slovic (1987), os conflitos podem ser resultantes do descompasso existente sobre o conceito de risco entre população e especialistas, e que a comunicação e a gestão do risco podem fracassar por falta de conexão e reciprocidade entre especialistas e população.

A escassez hídrica ocorrida entre 2013 e 2015 na Região Metropolitana de Campinas, enquanto um desastre, vai além de uma crise de disponibilidade dada pelos baixos índices pluviométricos e de uma crise dos diferentes usos da água, mediada por diversos conflitos. Há que se considerar sua construção social, a partir de processos históricos, culturais, econômicos e políticos que atuaram e continuam tangenciando o processo de produção de condições desiguais de acesso à água, a sua manutenção e a sua reprodução. Em um momento de escassez hídrica, medidas emergenciais, que desconsideram a construção social do problema, pouco têm efeito na resolução de conflitos, perpetuando as condições de vulnerabilidade da população afetada.

[I] https://orcid.org/0000-0003-2675-0566

Consultora autônoma. São Paulo, SP/Brasil. tathimay@gmail.com

\section{Notas}

(1) O presente trabalho faz parte de uma discussão mais aprofundada sobre o tema apresentada na tese de Anazawa (2017), cujo projeto de doutorado foi financiado pelo Conselho Nacional de Desenvolvimento Científico e Tecnológico (CNPq).

(2) Essas discussões fazem parte da tese de Anazawa (2017).

(3) A lei na íntegra está disponibilizada em: http://www.al.sp.gov.br/repositorio/legislacao/lei/1991/ lei-7663-30.12.1991.html.

(4) A lei na íntegra está disponibilizada em: http://www.planalto.gov.br/ccivil_03/leis/L9433.htm. 
(5) Disponível em: http://www.comitespcj.org.br/. Acesso em: 4 ago 2015.

(6) As intervenções ocorridas e as correções dos cálculos estão disponibilizadas em: http://www2. sabesp.com.br/mananciais/DivulgacaoSiteSabesp.aspx. Acesso em: 6 set 2015.

(7) A informação sobre os prazos, agenda das discussões sobre a renovação da outorga e as resoluções podem ser encontradas em: http://www2.ana.gov.br/Paginas/imprensa/noticia. aspx?id_noticia=13177. Acesso em: 1 fev 2017.

(8) Para maiores informações sobre o histórico e resoluções, consultar: http://www2.ana.gov.br/ Paginas/servicos/saladesituacao/v2/glossariocantareira.aspx. Acesso em: 2 jan 2016.

(9) Ação Civil Pública no 0005930-92.2014.4.03.6109. Disponível em: http://www.mpsp.mp.br/ portal/page/portal/cao_urbanismo_e_meio_ambiente/GTEaguas/GTEaguas_AcoesCivPubl/ ACP_VOLUME_MORTO_PETICAO_INICIAL_com_bookmarks.pdf. Acesso em: 2 jan 2016.

(10) Para maiores informações sobre as vazões de retiradas segundo a outorga de 2004, consultar: http://www2.ana.gov.br/Paginas/servicos/saladesituacao/v2/faqcantareira.aspx. Acesso em: 2 jan 2017.

(11) Os decretos citados podem ser consultados em: https://leismunicipais.com.br/legislacaomunicipal/4842/leis-de-campinas. Acesso em: 2 fev 2017.

\section{Referências}

ANA - AGÊNCIA NACIONAL DE ÁGUAS (2015). Encarte especial sobre a crise hídrica. Brasília, DF.

ANAZAWA, T. M. (2017). A grave escassez hídrica e as dimensões de um desastre socialmente construído: a Região Metropolitana de Campinas entre 2013-2015. Tese de doutorado. Campinas, Universidade Estadual de Campinas.

CARMO, R. L. do (2001). A água é o limite? Redistribuição espacial da população e recursos hídricos no Estado de São Paulo. Tese de doutorado. Campinas, Universidade Estadual de Campinas.

(2014). “Urbanização e desastres: desafios para a segurança humana no Brasil”. In: CARMO, R. L. e VALENCIO, N. (orgs.). Segurança humana em contextos de desastres. São Carlos, Rima.

CARMO, R. L. e HOGAN, D. J. (2006). “Questões ambientais e riscos na Região Metropolitana de Campinas". In: CUNHA, J. M. P. (org.). Novas metrópoles paulistas: população, vulnerabilidade e segregação. Campinas, Nepo/Unicamp.

CASTELLANO, M. e BARBI, F. (2006). Avanços na gestão compartilhada dos recursos hídricos nas bacias dos rios Piracicaba, Capivari e Jundiaí. São Paulo em Perspectiva. São Paulo, v. 20, n. 2, pp. 46-58.

CBH-PCJ - COMITÊ DAS BACIAS HIDROGRÁFICAS DOS RIOS PIRACICABA, CAPIVARI E JUNDIAÍ (2015). Relatório de situação dos recursos hídricos. Disponível em: http://www.agenciapcj.org.br/docs/ relatorios/relatorio-situacao-2015.pdf. Acesso em: 21 mar 2017. 
CEMADEN (2015). Relatório da situação atual e projeção hidrológica para o Sistema Cantareira. Cachoeira Paulista.

COSTA, M. T. (2014a). Falta d'água já afeta 1,1 milhão na região de Campinas. Correio Popular, 17 out. Disponível em: http://correio.rac.com.br/_conteudo/2014/10/capa/campinas_e_rmc/215288falta-d-agua-ja-afeta-1-1-milhao-na-regiao-de-campinas.html. Acesso em: 2 mar 2017.

(2014b). Falta d'água ameaçou Campinas 77 vezes. Correio Popular, 2 dez. Disponível em: http://correio.rac.com.br/_conteudo/2014/12/capa/campinas_e_rmc/227211-falta-d-aguaameacou-campinas-77-vezes.html. Acesso em: 2 mar 2017.

(2014c). Crise da água completa um ano sem saída a curto prazo. Correio Popular, 10 dez. Disponível em: http://correio.rac.com.br/_conteudo/2014/12/capa/campinas_e_rmc/228850crise-da-agua-completa-um-ano-sem-saida-a-curto-prazo.html. Acesso em: 2 mar 2017.

CULTURA CARTA CAMPINAS (2015). MP investiga publicidade da Sanasa que incentivou consumo de água na crise hídrica. Carta Campinas, 16 dez. Disponível em: http://cartacampinas.com. br/2015/10/mp-investiga-publicidade-da-sanasa-que-incentivou-consumo-de-agua-na-crisehidrica/. Acesso em: 2 mar 2017.

DYNES, R. R. e DRABEK, T. E. (1994). The structure of disaster research: its policy and disciplinary implications. International Journal of Mass Emergencies and Disasters, v. 12, n. 1, pp. 5-23.

EMPINOTTI, V. L.; JACOBI, P. R. e FRACALANZA, A. P. (2016). Transparência e a governança das águas. Estudos Avançados. São Paulo, v. 30, n. 88, pp. 63-75.

FRACALANZA, A. P. e FREIRE, T. M. (2015). Crise da água na Região Metropolitana de São Paulo: a injustiça ambiental e a privatização de um bem comum. Geousp: Espaço e Tempo (Online). São Paulo, v. 19, n. 3, pp. 464.

G1 CAMPINAS E REGIÃO. G1 (2015). Reajuste de 15\% na conta de água em Campinas começa a valer na segunda - notícias em Campinas e Região. Disponível em: http://g1.globo.com/sp/campinasregiao/noticia/2015/08/reajuste-de-15-na-conta-de-agua-em-campinas-comeca-valer-nasegunda.html. Acesso em: 2 mar 2017.

HANNIGAN, J. (2006). Environmental sociology. Londres, Routledge.

IBGE - Instituto Brasileiro de Geografia e Estatística (2011). Censo Demográfico 2010. Características da população e dos domicílios: resultados do universo. Disponível em: http://biblioteca.ibge. gov.br/visualizacao/periodicos/93/cd_2010_caracteristicas_populacao_domicilios.pdf. Acesso em: 21 dez 2016.

IDS - INSTITUTO DEMOCRACIA E SUSTENTABILIDADE (2014). Mesa Redonda reúne especialistas e imprensa para discutir abordagens e alternativas para a crise hídrica em SP, 2014. Disponível em: www.idsbrasil.net/pages/viewpage. action?pageld=30474259. Acesso em: 2 jun 2015.

JACOBI, P. R.; CIBIM, J. e LEÃO, R. de S. (2015). Crise hídrica na Macrometrópole Paulista e respostas da sociedade civil. Estudos Avançados. São Paulo, v. 29, n. 84, pp. 27-42.

JACOBI, P. R.; CIBIM, J. C. e SOUZA, A. N. (2016). Crise da água na região metropolitana de São Paulo-2013/2015. Geousp: Espaço e Tempo (Online). São Paulo, v. 19, n. 3, pp. 422-444.

LAVELL THOMAS, A. (1993). “Ciencias sociales y desastres naturales en America Latina: un encuentro inconcluso". In. MASKREY, A. (org.). Los desastres no son naturales. LaRED - Red de Estudios Sociales en Prevencion de Desastres en America Latina. 
LAVELL THOMAS, A. e FRANCO, E. (1996). Estado, sociedad y gestión de los desastres en América Latina. En busca del paradigma perdido. Lima, Peru, La Red-FLACSO-IT Peru, Lahmann.

MARCHEZI, F. (2014). Estiagem deixa 5 municípios de SP em emergência e um em calamidade pública. UOL Notícias Cotidiano. Disponível em: https://noticias.uol.com.br/cotidiano/ ultimas-noticias/2014/08/14/estiagem-deixa-5-municipios-de-sp-em-emergencia-e-um-emcalamidade-publica.htm. Acesso em: 2 mar 2017.

MARENGO, J. A. e ALVES, L. M. (2015). Crise hídrica em São Paulo em 2014: seca e desmatamento. Geousp: Espaço e Tempo (Online). São Paulo, v. 19, n. 3, pp. 485-494.

MARTíN, M. (2015). Durante a crise hídrica, casos de diarreia se multiplicam em São Paulo. Disponível em: http://brasil.elpais.com/brasil/2015/07/10/politica/1436557827_946009.html. Acesso em: 2 mar 2017.

MASKREY, A. (org.) (1993). Los desastres no son naturales. LaRED - Red de Estudios Sociales en Prevencion de Desastres en America Latina. Bogotá, Tercer Mundo Editores.

QUARANTELLI, E. L. (ed.) (1998). What is a disaster? Londres, Routledge.

QUARANTELLI, E. L. e DYNES, R. R. (1977). Response to social crisis and disaster. Annual Review of Sociology, v. 3, pp. 23-49.

ROMERO, G. e MASKREY, A. (1993). "Como entender los desastres naturales". In: MASKREY, A. (org.). Los desastres no son naturales. LaRED - Red de Estudios Sociales en Prevencion de Desastres en America Latina.

ROSSI, A. (2015). Sanasa diz que elevou tarifa de água porque há menos consumo. Disponível em: http://portal.tododia.uol.com.br/_conteudo/2015/07/cidades/83649-sanasa-diz-que-elevoutarifa-de-agua-porque-ha-menos-consumo.php. Acesso em: 2 mar 2017.

SAMPAIO, L. (2014). Moradores fazem protesto em Campinas contra falta de água - 14/10/2014 Cotidiano. Folha de São Paulo. Disponível em: about:reader?url=http\%3A\%2F\%2Fwww1.folha. uol.com.br\%2Fcotidiano\%2F2014\%2F10\%2F1532248-moradores-fazem-protesto-em-campinascontra-falta-de-agua.shtml. Acesso em: 2 mar 2017.

SANASA (2015). Campanha informa a situação do abastecimento em Campinas. Disponível em: <http://www.sanasa.com.br/conteudo/conteudo2.aspx?par_nrod=2070\&flag=P-A>. Acesso em: 2 mar 2017.

SEMEGHINI, M. (2014). Sanasa recebe 290 denúncias de desperdício no fim de semana. Disponível em: http://correio.rac.com.br/_conteudo/2014/02/capa/campinas_e_rmc/152626-sanasa-registra290-denuncias-no-fim-de-semana.html. Acesso em: 2 mar 2017.

SILVA, D. D. e PRUSKI, F. F. (eds.) (2000). Gestão de recursos hídricos: aspectos legais, econômicos, administrativos e sociais. Brasília, DF, Secretaria de Recursos Hídricos; Viçosa, MG, Universidade Federal de Viçosa; Porto Alegre, Associação Brasileira de Recursos Hídricos.

SLOVIC, P. (1987). Perception of risk. Science. Washington, DC, v. 236, n. 4799, pp. 280-285.

VALENCIO, N. F. L. S. (2009). "Da 'área de risco' ao abrigo temporário: uma análise dos conflitos subjacentes a uma territorialidade precária". In: VALENCIO, N.; SIENA, M.; MARCHEZINI, V. e GONÇALVES, J. C. (orgs.). Sociologia dos desastres - construções interfaces e perspectivas para o Brasil. São Carlos, Rima. 
VALENCIO, N. F. L. S. (2013). Sociologia dos desastres: construção, interfaces e perspectivas no Brasil. São Carlos, RiMa.

(2014). Desastres: tecnicismo e sofrimento social. Ciênc. saúde coletiva. Rio de Janeiro, v. 19, n. 9, pp. 3631-3644.

Texto recebido em 18/fev/2018

Texto aprovado em 6/abr/2018 
